3

4

5

6

7

8

9

10

11

12

13

14

15

16

17

18

19

20

21

22

23 Abstract

24 Coastal ecosystems, such as estuaries, salt marshes, mangroves, and seagrass meadows,

\section{True value of estuarine and coastal nurseries for fish: incorporating complexity and dynamics}

\footnotetext{
${ }^{1}$ School of Marine and Tropical Biology, James Cook University, Townsville, Queensland 4811, Australia

${ }^{2}$ CSIRO Land and Water, ATSIP Building, James Cook University, Townsville, Queensland 4811, Australia

${ }^{3}$ Southern Seas Ecology Laboratories, School of Earth and Environmental Sciences, DX 650418, University of Adelaide, Adelaide, South Australia 5005, Australia

${ }^{4}$ Australian Rivers Institute - Coasts \& Estuaries, Griffith School of Environment, Griffith University, Gold Coast, Queensland 4222, Australia
}

*Corresponding author: email: Marcus.sheaves@ @cu.edu.au, telephone: +61 (07) 47814144 , fax: +61 (07) 47251570

Abstract

comprise some of the world's most productive and ecologically significant ecosystems.

6 Currently, the predominant factor considered in valuing coastal wetlands as fish habitats is

27 the contribution they make to offshore, adult fish stocks via ontogenetic migrations. 
However, the true value of coastal nurseries for fish is much more extensive, involving several additional, fundamentally important ecosystem processes. Overlooking these broader aspects when identifying and valuing habitats risks suboptimal conservation outcomes, especially given the intense competing human pressures on coastlines and the likelihood that protection will have to be focussed on specific locations rather than across broad sweeps of individual habitat types. We describe 10 key components of nursery habitat value grouped into three types: 1) Connectivity and population dynamics (includes connectivity, ontogenetic migration and seascape migration), 2) Ecological and ecophysiological factors (includes ecotone effects, ecophysiological factors, food/predation trade-offs and food webs), and 3) Resource dynamics (includes resource availability, ontogenetic diet shifts and allochthonous inputs). By accounting for ecosystem complexities and spatial and temporal variation, these additional components offer a more comprehensive account of habitat value. We explicitly identify research needs and methods to support a broader assessment of nursery habitat value. We also explain how, by better synthesising results from existing research, some of the seemingly complex aspects of this broader view can be addressed efficiently.

Keywords: Nursery ground - Ecosystem mosaic - Coastal wetland - Estuary - Fish

\section{Introduction}

Coastal wetlands comprise some of the most valuable ecosystems on the planet (van den Belt 2011, Elliott \& Whitfield 2011), and yet are among the most threatened (Bassett et al. 2013). Their position at the interface of land and sea means they occupy locations that are highly prized by humans, leading to unprecedented and rapidly increasing threats from intense 
51 population pressure, rapid, large-scale development, and climate change (Hughes et al. 2009,

52 Corn and Copeland 2010). This conjunction of high value and intense threats makes a detailed understanding of the functioning of coastal wetlands essential if they are to be managed and protected for future generations (Elliott \& Kennish 2011).

One value that is increasingly recognised for all types of coastal wetlands, whether they are estuaries, saltmarshes, mangrove forests, seagrass meadows or floodplain swamps, is their role as nursery grounds for aquatic species of immense ecological, cultural and economic importance (Beck et al. 2001, Mumby and Hastings 2008). This nursery value stems from the provision of habitat, refuge, food, favourable physical conditions and advantageous hydrodynamics (Nagelkerken et al. in press). However, the provision of these services is complex. Not only do the values manifest at a variety of scales (e.g. habitat or food provided at a local scale, versus physical conditions at a whole of ecosystems level) but, rather than being a function of a single habitat, their values are usually conferred by a mosaic of interacting habitats (Sheaves 2009, Berkström et al. 2012) and may rely on processes or inputs derived from well beyond the wetlands themselves (Beger et al. 2010). Many of the processes that underpin nursery function may not be a feature of a spatial habitat at all; for example, reliance on the delivery of allochthonous sources of production to support food webs (Connolly et al. 2005), or the temporal coincidence of recruitment and the availability of suitable prey resources (Robertson and Duke 1990). Nursery function is further complicated by the diversity of life-history strategies of the species occupying these systems (Elliott et al. 2007, Potter et al. in press).

Although estuarine and coastal ecosystems have long been recognised as nurseries for fish and crustaceans (Boesch and Turner 1984), it was not until the seminal work of Beck et al. (2001) that the concept was formalised. However, the ideas of Beck et al. (2001) and their modification by Dahlgren et al. (2006) focus on one aspect of nursery ground value; the 
supply of juveniles from discrete spatial units of nursery habitat to adult populations. Such approaches only consider contribution that can be measured in terms of the movement of juvenile numbers/biomass, so do not capture the complex dynamics that support nursery function. While these approaches represent a significant step forward, comprehensive nursery identification and valuation requires that the complex, dynamic nature of nursery ground function needs to be recognised (Able 2005, Mumby and Hastings 2008, Sheaves 2009, Potter et al. in press) and consolidated into identification and valuation if nursery function is to be maintained in the face of ever increasing anthropogenic pressures (Nagelkerken et al. in press).

There are two aspects to the value of nursery grounds to fish: (1) their value in supporting successful nursery ground occupation, and (2) the value to recipient populations and ecosystems (Fig. 1). Most current concepts of nursery ground value (e.g. Beck et al. 2001, Dahlgren et al. 2006) relate to the output of juveniles from nursery grounds that reach offshore (e.g. Reis-Santos et al. 2012), but the mechanisms that drive this contribution to recipient populations are incompletely understood. Recognition of the significance of the processes which regulate juvenile populations within nursery habitats is nothing new (e.g. Minello et al. 2003), and the need to evaluate this information in the context of entire lifecycles is increasingly recognised (Huijbers et al. 2013, Baker et al. 2014, Vasconcelos et al. in press). However, current approaches to the valuation of nurseries ultimately treat the processes driving nursery function as a black box by simply measuring what emerges at the end as emigrants to the adult populations. The resulting rankings of nursery grounds fail to provide managers with information on how to protect key processes that underpin nursery value and function. Furthermore, focusing management and further research on the identified 'important' nursery habitats is risky because the habitat units identified will rarely contain all the elements that support the nursery function we aim to protect. 
101 Nursery ground value is the net result of a complex of interacting factors that vary from situation to situation. Some involve seascape structure and function directly (Hammerschlag et al. 2010), but others extend to include complex ecological interactions and resource dynamics, and often involve a complex of cross-habitat and cross-ecosystem movements. This complexity needs to be considered in the context of differences in the composition of fish assemblages using coastal nurseries in different parts of the world (Sheaves 2012, Potter et al. in press) that is likely to result in different mixes of factors being important in different regions. Understanding this complexity and the relative importance of different factors, is the key to meaningful nursery identification and valuation, and is the raw material needed to inform population conservation decision support systems (Beger et al. 2010). Conversely, a lack of evaluation of the complexity is the recipe for superficial assessment (Harris and Heathwaite 2012) that is likely to miss the most critical contributors to value. Consequently, we build on earlier work to develop a framework for a more comprehensive understanding of nursery ground value, by considering the range of contributions of nurseries to sustaining needs to be integrated and extended. 
At an operational level of supporting the lives of juvenile fish, nurseries comprise a complex mosaic of interacting habitat units and the connectivities enabling their interaction (Sheaves 2009). The importance of juvenile habitat is well recognised, and is a key driver for the identification of essential fish habitat in the USA (e.g. Froeschke et al. 2013) and Europe (Vasconcelos et al. in press). However current definitions for identifying nursery habitats emphasise the habitats which leave a distinctive chemical signature or are the habitats from which juveniles can be most readily sampled (Gillanders 2005). This disregards the fact that many aquatic species shift habitats during their time within the nursery (Kimirei et al. 2011), and that other critical habitats might only be occupied transiently (Tupper 2007) or indirectly support nursery value (Connolly et al. 2005).

Connectivity (Fig. 1a): Ontogenetic habitat shifts, the use of transitory and temporary habitats (Potter et al. in press), and the use of a mosaic of habitats within the nursery seascape (Nagelkerken et al. in press) attest to the central importance of connectivity in supporting nursery ground value (Vasconcelos et al. 2011). Yet connectivity is more than just the movement of individuals among habitats; it is a facilitator that enables a variety of critical ecological functions to support nursery value (Sheaves 2009). For instance, deriving maximal nursery ground value relies on spatio-temporal matching between the functional requirement to use the particular habitat (e.g. refuge), the occurrence of appropriate resources (e.g. flooded marsh surface) and physical conditions in the habitat (e.g. oxygen levels), and it is connectivity that allows this complex matching to occur. The facilitating role of connectivity is pervasive (Beger et al. 2010), and it is a key factor supporting most ecological interactions conferring nursery ground value.

Ontogenetic migrations (Fig. 1b): Ontogenetic migrations occur at a range of scales, from movements along freshwater to marine gradients (Russell and Garrett 1985, McBride et al. 2001, Davis et al. 2012), and movements within local habitat mosaics (Nagelkerken 2009, 
Grol et al. 2011). Local scale migrations include both easily identifiable meso-term habitat shifts (e.g. seagrass to mangrove to patch reefs (Nagelkerken et al. 2000a)) and ephemeral habitat occupancy (e.g. initial settlement habitats (Dahlgren and Eggleston 2000, Grol et al. 2011)) that is more difficult to detect. Not only do ontogenetic habitat shifts exist across a range of dependencies, from facultative (Milton et al. 2008) to more obligate (Potter et al. in press), but they may vary spatially (Kimirei et al. 2011). For instance, Haemulon flavolineatum, one of the most common Caribbean ontogenetic shifters, moves from rubble habitat to seagrass beds to mangroves to rocky substratum in some geographic locations (Grol et al. 2011), but from rubble habitat to sea urchin spines to seagrass beds to lagoonal patch reefs in others (Ogden 1988).

Seascape migrations (Fig. 1c): On shorter time scales, feeding migrations and movements to refugia are vital facilitators of key nursery functions, and connect multiple habitats within the nursery seascape (Sheaves 2005, Verweij and Nagelkerken 2007). In situations where large tidal differences occur, intertidal habitats such as salt marsh or mangrove roots are only available periodically (Minello et al. 2012), leading to regular tidal migrations. Even in cases where tides do not play a major role, many organisms show predictable diurnal movements between shelter habitats and foraging grounds (Hammerschlag et al. 2010). Seascape structure, the spatial patterning of prey and predator species, and the hydrodynamics and geomorphology of the ecosystem all play important roles in structuring such animal movements across habitats (Nagelkerken 2007, Baker et al. 2013).

\section{Ecological and Ecophysiological Factors}

Ecotone effects (Fig. 1d): Ecotones are important contributors to nursery ground value.

Indeed, estuarine nurseries occur in transitional waters between freshwater reaches and the sea and have been defined as traditional ecosystems in their own right (Basset et al. 2013). 
174 Animal communities often show strong spatial patterning within the seascape, and it is especially at the edges of habitats where highest species richness and densities are observed (Dorenbosch et al. 2005, Johnston and Sheaves 2007). For example, fish densities in seagrass beds can decrease with distance away from patch reefs (Valentine et al. 2008), and the highest fish and crustacean densities are found at the seaward fringes of salt marsh (Minello et al. 2003) and mangroves forests (Vance et al. 1996). As boundaries that need to be crossed moving between habitats, ecotones are also areas where risks can be greatest (Hammerschlag et al. 2010), and so are points where population structuring factors like predation focus can be particularly influential (Sheaves 2005, Baker and Sheaves 2009b).

Ecophysiological factors (Fig. 1e): Physical factors and physiological abilities are critical in determining spatial (Sheaves 1996a, Harrison and Whitfield 2006) and temporal (Attrill and Power 2004) patterns of nursery ground occupancy. This manifests at a diversity of scales; for instance relating to ontogeny of habitat use (McBride et al. 2001), seasonal occurrence of necessary physical conditions (Davis et al. 2012) and nutrients (Abrantes and Sheaves 2010), long-term patterns of nursery utilisation (Sheaves 1998), variations in optimal nursery habitats (Hurst and Conover 2002), or responses to multi-year climatic cycles (Sheaves et al. 2007). Consequently, in many systems nursery provision will change substantially over time (Minello et al. 2012), providing advantage to different species under different conditions. Differing behavioural and physiological abilities allow different species, and even different ontogenetic stages, to access and use different nursery grounds or use nursery grounds in different ways. Air breathing organs in species such as tarpon (Megalops spp.) allow them to utilise hypoxic wetland nurseries (Seymour et al. 2008), while barramundi (Lates calcarifer) juveniles are able to access hypersaline wetlands from which predators and competitors are excluded (Russell and Garrett 1985). Even in deeper estuarine waters hypoxia can exclude species from habitats during periodic hypoxic events (Pihl et al. 1991, Switzer et al. 2009). In 
response, many estuary species can detect and avoid areas of low dissolved oxygen concentration (Wannamaker and Rice 2000). Not only do different salinity preferences contribute to nursery habitat partitioning by co-occurring juvenile fish (Davis et al. 2012), but physical conditions can have substantial influences on growth rates of juveniles (Del ToroSilva et al. 2008), with salinity and temperature regimes often having more substantial influences on growth than diet (Baltz et al. 1998). Eco-physiological effects can be complex, interacting with ecological processes to effect changes in nursery value for different juvenile stages. For instance, ecophysiological differences allow young juvenile California halibut, Paralichthys californicus, to occupy estuaries with abundant prey and few predators from which larger juveniles are excluded because of narrower salinity and temperature tolerances (Madon 2002).

Food/Predation Trade-Offs (Fig. 1f): Juveniles utilising nurseries face a complex trade-off between the need to obtain sufficient, appropriate prey, and minimising predation risk (Sogard 1992, Baker and Sheaves 2007). This trade-off can profoundly affect nursery ground value, and the quantity and quality of sub-adults migrating to adult habitats (Walters and Juanes 1993, Kimirei et al. 2013). The need to access prey-rich areas can initiate or necessitate behaviour that exposes juveniles to increased predation risk (Alofs and Polivka 2004, Sheaves 2005) or to forage in areas that support poor growth rates (Sogard 1992, Harter and Heck 2006). In fact, the underlying mechanisms that drive habitat shifts are often related to minimizing the ratio of mortality risk to growth rates (Werner and Hall 1988, Halpin 2000), because profitable habitats for food acquisition are often riskier in terms of probability of predator encounter (Hammerschlag et al. 2010). Predation is usually the largest source of mortality for juvenile fish (Harter and Heck 2006), so high risk areas, such as transition zones between refuge and feeding areas (Hammerschlag et al. 2010) may represent ecological bottlenecks. For example, predatory activity at these locations can control the 
supply of recruits to nursery grounds (MacGregor and Houde 1994, Brown et al. 2004) and the supply of juveniles from nursery grounds to adult populations (Yurk and Trites 2000, Friedland et al. 2012), and so provide the opportunity for predatory control of nursery populations (Baker and Sheaves 2009b). In addition, these refuge-food acquisition trade-offs vary between species (Camp et al. 2011) meaning that nursery ground values may differ markedly depending on the species involved.

Food webs (Fig. 1g): Predators have a strong top-down control on food webs. While nurseries have typically been assumed to harbor few predators, recent studies have shown a more complex picture (Baker and Sheaves 2009a, Dorenbosch et al. 2009). Although standing stock of predators may be low much of the time, immigrating predators from adjacent systems can produce profound predatory effects on nursery fish during their short foraging forays (Baker and Sheaves 2009a). Moreover, many nursery species shift ontogenetically to higher piscivory while still occupying nurseries (Baker and Sheaves 2009a). The spatio-temporal presence of predators and their specific gape sizes will determine to what degree they control fish populations in nurseries. Secondly, interspecific interactions may determine which species ultimately are responsible for greatest export to adjacent ecosystems. Recruitment of nursery fish may be highly variable in time, and feeding habitat and food availability may be limiting during nursery occupancy (Igulu et al. 2013). Competitive exclusion from optimal foraging habitats among species may be an important determinant of the winners and losers of nursery habitat use in terms of growth, survival, and successful movement to consecutive habitats.

\section{Resource Dynamics}

The availability, distribution and quality of resources within the nursery are critical parameters underpinning nursery ground value, the pattern of use of resources, and ultimately 
the outcome of nursery ground residence. Resource use is complex, varying along stagespecific, time-specific and purpose-specific axes.

Resource availability (Fig. 1h): Nursery grounds are often nutritionally rich ecosystems maximizing cohort growth during nursery ground residence (Yanez-Arancibia et al. 1994), and marine organisms invest heavily in rapid growth during their early life stages. Prey quantity and quality affect growth (Sogard 1992, Scharf et al. 2006) because of substantial differences in the energetic value of different prey types (Ball et al. 2007). Although fish may be able to switch to alternative prey (Gartland et al. 2006), there are limits to this ability to adapt (Nobriga and Feyrer 2008), and particular prey may be required at particular life stages (Robertson and Duke 1990, Baker and Sheaves 2005). Consequently, the quality, quantity and availability of food resources is an important factor in nursery value, although food acquisition often necessitates trade-offs with predation avoidance (see above). High quality nursery grounds are also those that provide optimal habitats relative to the full range of lifehistory functions (Nagelkerken and van der Velde 2002, Nagelkerken et al. in press), such as juvenile settlement (Dahlgren and Eggleston 2000, Grol et al. 2011), foraging (Nagelkerken et al. 2000b, Harter and Heck 2006) and refuge (Ellis and Gibson 1995, Sheaves 1996b, Gorman et al. 2009).

Ontogenetic diet shifts (Fig. 1i): Complex seascape dynamics, with juveniles obtaining resources from different habitats during different phases of their nursery residence, mean that the development of complicated and variable food webs is inevitable (Nagelkerken et al. 2006). Due to ontogenetic dietary shifts, many juveniles change their trophic identity during nursery occupation. Profound changes in diet over development mean they may not even participate in the same trophic web throughout nursery occupation. For example, juvenile Platycephalus fuscus initially feed almost entirely on amphipods and so participate in a food web based on benthic productivity, while larger juveniles in the same habitat switch to 
feeding extensively on planktivorous fish (Baker and Sheaves 2005). Such ontogenetic diet shifts are widespread among estuarine and coastal fishes (Elliott et al. 2007), and the availability of the different food items that are preferentially selected through ontogeny is an important driver of the realized growth during nursery occupancy.

Allochthonous inputs (Fig. 1j): In marine systems water is an effective vector for the movement of energy and nutrients among habitats, allowing substantial trophic subsidies that affect the structure of animal populations in recipient systems (Deegan 1993). In some situations, animals are sustained by food webs based on autotrophic production within their habitat (e.g. juvenile fish in seagrass meadows in the Mediterranean (Vizzini et al. 2002), and animals on saltmarshes in subtropical Australia (Guest and Connolly 2004)). Often, however, nutrition is derived ultimately from plants or algae growing elsewhere. Organic matter from seagrass meadows can sustain food webs in adjacent habitats (Heck et al. 2008), supporting production in both temperate (e.g. Connolly et al. 2005) and tropical (e.g. Melville and Connolly 2005) systems, while mangroves also have been shown to support fish production in adjacent estuarine (Abrantes and Sheaves 2009a) or coastal waters (Bouillon et al. 2008) in certain situations. Stable isotope analysis has demonstrated both the detrital pathway for this transfer and the fact that movement of nutrients can also occur through in-welling from coastal to intertidal waters (Connolly et al. 2005).

\section{The Support of Recipient Populations and Ecosystems by Nursery Grounds}

The conventional view of nursery ground value (e.g. Heck et al. 1997, Beck et al. 2001) emphasises the contribution of juveniles from inshore nurseries to recipient (usually offshore) populations, and its crucial role in supplying adult populations with new individuals. The migration of juveniles also represents the biologically-mediated export of nutrients, incorporated into juvenile biomass during nursery residence, donated to offshore systems 
to be the best integrative measure of the contribution of juveniles to future generations.

However, the numbers and biomass of individuals that reach adult stocks represent only part of the contribution that juveniles using nursery grounds make to recipient populations and ecosystems (Fig. 1, 2).

Diverse trophic contributions: From the moment of recruiting to the nursery ground the abundance of a cohort is continually and exponentially pruned back by mortality (YanezArancibia et al. 1994, Doherty et al. 2004). As abundance declines individual biomass increases until a very small number (relative to those recruiting) of large individuals emigrate from the nursery ground (Yanez-Arancibia et al. 1994, Sheaves et al. 2013) transferring their accumulated biomass to offshore habitats (Deegan 1993), where they may be ultimately measured as contributing to adult stocks (Beck et al. 2001) (Fig. 2a). However, most individuals, and a significant proportion of the biomass, do not survive to emigrate (Deegan 1993, Yanez-Arancibia et al. 1994, Baker et al. 2014) and so do not figure in calculations of exported biomass. However, these individuals are critical to nursery ground value by forming what is essentially a sacrificial nursery component that allows other nursery individuals to survive (Sandin and Pacala 2005, Svenning et al. 2005) (Fig. 2b). In doing so, they provide food for juvenile predators within the nursery (Minello et al. 1989, Baker and Sheaves 2005) (Fig. 2c) that ultimately translocate accumulated nutrients offshore during their ontogenetic migrations (Thorson 1971, Werry et al. 2011) (Fig .2a), and for transient predators from offshore feeding within the nursery (Begg and Hopper 1997) that return offshore exporting biomass accumulated in the nursery ground (Fig. 2d). These juveniles also 319 form critical links in nursery food webs (Abrantes and Sheaves 2009a, b) (Fig. 2e), provide a vehicle for transferring production among habitats (Rozas and LaSalle 1990), and form critical components of trophic relays where intermediate prey link production sources in one 
habitat with higher consumers in another (Kneib 1997) (Fig. 2f). When viewed this way, the nursery cohort is largely made up of individuals comprising a critical resource in the trophic functioning of the nursery and adjacent connected ecosystems, with the survivors representing surplus individuals not consumed in powering the system. Valuing a nursery based only on the biomass of individuals that reach adult stocks clearly overlooks a diversity of processes critical to the function of these systems (Sheaves et al. 2006) because the relative contributions from different nurseries of individuals that ultimately reach the adult stocks does not reflect the full production output of each nursery or their contributions to the support of other species. Although specifically quantifying all the components of biomass transfer will rarely be practical given our current knowledge bases, quantification is not the primary issue. Recognising that the true value of trophic contributions from nursery grounds is much more extensive than can be measured as exported biomass alone is critical for the effective management of nursery function, and to developing approaches to begin to quantify those additional contributions.

Export of process: The influence of nursery grounds on offshore ecosystems is not confined to the contribution of individuals to adult populations or biomass translocation, but extends to effects on key processes in the recipient ecosystems (Fig. 2g). Connectivity to mangrove nursery grounds influences overall community structure and resilience on many Caribbean coral reefs. Because dominant herbivores have an obligate mangrove nursery phase the presence of mangroves has a substantial impact on the numbers of herbivores on adjacent reefs, thus regulating the beneficial effects of herbivory in those systems (Mumby et al. 2004), and greatly increases resilience of mid-shelf reefs to severe hurricane disturbances (Mumby and Hastings 2008). At the other end of trophic webs, as well as contributing to the export of biomass, the movement of juvenile bull sharks, Carcharhinus leucas, from coastal 
nurseries (Curtis et al. 2011, Heupel and Simpfendorfer 2011) represents the supply of subadult and adult high-level predators (Marshall and Bennett 2010) that can be major influences on offshore predation dynamics (Hunsicker et al. 2012) and severely impact lower trophic levels through trophic cascades (Myers et al. 2007). The export of process extends to biological controls, with juvenile grouper from mangrove nurseries having the potential to control populations of invasive lionfish on Caribbean coral reefs (Maljkovic et al. 2008). The growing awareness of the complexity of interactions between different environmental realms and the importance of connectivities at all scales in supporting ecological functioning (Beger et al. 2010) suggests that many more effects of nurseries on ecological processes in recipient ecosystems are likely to be recognised as our understanding of linkages between ecosystems becomes more sophisticated. As with developing a more complete understanding of the spectrum of contributions from trophic interactions, developing a more complete understanding of the process links emanating from nursery grounds to influence recipient ecosystems is critical to developing a comprehensive understanding of the true value of nursery grounds.

\section{Current situation: Approaches available to identify the full value of}

\section{nurseries}

The value of any juvenile habitat depends on its complex contributions to the sustainability of populations and the functioning of replenishing and recipient ecosystems. Recognising the lack of a framework for identifying valuable nurseries, Beck et al. (2001) proposed an approach to rank nursery grounds based on the total biomass contributed from different putative nursery habitats. This was an important advance, recognising the need to compare contributions across all possible nursery habitats. However, this is only a first step, because comprehensive identification, valuation and management of estuarine and coastal nurseries 
for fish requires detailed understanding of the range of processes supporting nursery value (Jones et al. 2002), and of the full value of outputs to recipient ecosystems (Mumby and Hastings 2008). Additionally, while ranking nurseries may provide guidance for prioritising areas for conservation very broadly, it is of limited value for managers charged with maintaining nursery function in the face of impacts at specific locations. The increasingly urgent need to understand and maintain ecosystem function across the globe is driven far more by the need to manage ever-increasing anthropogenic impacts, and multiple coastal users with conflicting usages, to our environment than by a desire to totally protect functional ecosystem units. It would be better, therefore, if protection and management of nursery grounds is not based solely on a ranking of the relative value of different putative nurseries. The approach we are recommending aligns with the broader shift to managing marine systems to conserve ecosystem functioning rather than focusing on individual species or habitat units (Foley et al. 2010).

Determining the relative contributions of putative nurseries to adult stocks in terms of numbers or biomass can often be achieved via retrospective determination of movement of individuals from particular nurseries to the adult population using artificial or natural markers (Gillanders et al. 2003, Gillanders 2005). For example, otolith chemistry may distinguish occupation of one coastal bay or estuary rather than another (Yamane et al. 2010, Reis-Santos et al. 2012), or differentiate between use of particular salinity zones (Albuquerque et al. 2012, Webb et al. 2012), or distinguish use of particular seascape components (Gillanders and Kingsford 1996). However, while natural markers can be used to define spatial units contributing most biomass to recipient adult populations, they are really only able to identify areas that can be most easily distinguished (e.g. ones that leave an otolith chemical signature), and are unlikely to be able to identify important habitats occupied for short periods (e.g. initial settlement habitats (Dahlgren and Eggleston 2000, Grol et al. 2011)), 

et al. 2007)), and linkages and pathways among habitats (Nagelkerken 2007, Hammerschlag et al. 2010). Moreover, they provide little information on how habitats are used or on the processes and functions (e.g. food web resilience or resource dynamics) that are critical to nursery value but are not specifically related to a particular spatial unit.

There are also practical limitations to the use of ranking based on the contribution of spatial units. As well as providing scant information on process, approaches such as otolith microchemistry frequently do not allow identification of juvenile habitats at the scale where key processes operate, the scale used by the juveniles themselves, or at a scale amenable to management action (Gillanders et al. 2003). It will often not be feasible for management to protect the entire unit identified; all of one bay, all of one salinity zone or all of one seascape component. As a result, managers will often seek to minimize impacts within the unit identified as a nursery. However, many supporting processes and negative impacts arise well beyond a specific unit of habitat, so unless the specific values and supporting processes of particular sub-units and connectivities are known, such spatial prioritization is likely to fail. Ranking of nurseries assumes that nursery components have independent contributions to nursery value (Beger et al. 2010). However, the complex nature of nursery ground provision, with multifaceted interactions transcending individual spatial units, means that identification of nursery habitat cannot be approached as a static process in which individual habitats and life phases are singled out. Ignoring these interactions could be justified when it is possible to conserve a whole ecosystem (e.g. whole estuary or whole of coastal seascape) containing all units contributing to nursery function; as is the case with large protected areas. More often, management will need to work with much more specific units. The ranking process then provides little help, and may even be misleading because it suggests that one area can be protected at the expense of others. Even if ranking could be achieved at an appropriate scale 
to enable relative valuation of different spatial units, it intrinsically disregards the critical importance of interactions among ensembles of habitat units (Sheaves 2009, Grol et al. 2011), the importance of connectivity among the habitat units (Beger et al. 2010), and the importance of habitats only occupied transiently (Nagelkerken et al. in press).

\section{Solutions: Approaches available to identify the true value of nurseries}

Determining how nursery value is influenced by connectivity, habitat type, habitat diversity, ecological interactions and trophic process seems like a complex task, but the type of information needed is already being collected; it just needs to be recombined, extended and refocused specifically on understanding nursery function. Not only can particular techniques contribute to understanding different aspects of nursery value (columns of ticks in Table 1) but combining various approaches can provide rich and extensive detail on specific aspects of nursery value (rows of ticks in Table 1).

To illustrate: connectivity studies using natural and artificial markers are becoming the principal techniques for determining biomass or numeric contributions from alternative nurseries to adult stocks (see above). However, marker studies have broader applicability (Table 1). Not only can they provide valuable inputs to understanding of nursery values ranging from ontogenetic migration to export of process but, when combined with other techniques, can contribute to a much deeper understanding of many aspects of nursery value. For example, combined with data including food web and fish-habitat relationship information, gleaned from stable isotope, dietary, observational and capture studies, they can provide information on ontogenetic migration, seascape migration, ecotone effects and connectivity itself (Table 1: rows 1a-2a). Similarly, contributions to juvenile predator biomass can be informed by: stable isotope and dietary studies used to define nursery food webs; dietary, observational, capture and tethering studies supplying information on predator 
identification and dynamics; and energetics and condition studies determining juvenile growth and health (Table 1: row 4d).

447 Many other solutions are indicated in Table 1. These are far from exhaustive and a variety of other possibilities and combinations of approaches are likely to be fruitful. In particular, it will usually be possible to define more specific detail when the ideas are applied to particular cases and the studies are considered in explicit spatial and temporal contexts. The possibilities of the information that can be gleaned using multiple techniques should expand quickly as new combinations of approaches are successfully applied to new problems.

\section{Conclusion}

A historical analysis of nursery-function studies shows progressive development of this important field: (1) the recognition that inshore habitats harbor high densities of juvenile fish (1970s; e.g. Weinstein 1979)), (2) the study of community structures of individuals nursery habitats (1980s; e.g. Robertson and Duke 1987), (3) the quantification of consecutive habitat usage by different life stages of fish (1990s; e.g. MacPherson 1998), (4) development of conceptual frameworks that identify critical nursery habitats (2000s; e.g. Beck et al. 2001), (5) recent studies that have used these frameworks in a quantitative way to identify primary nursery habitats (Tupper 2007, Huijbers et al. 2013). We are now at a stage where we need to take a step forward, building on these advances by developing an understanding of the processes that drive the productivity and maintenance of these identified key nurseries, and to go beyond valuation based simply on export of number or biomass, by incorporating the complex of factors that contribute to nursery value to provide a more comprehensive understanding of true nursery value. Only through this comprehensive understanding can we confidently identify the habitat mosaics and underlying connectivities/processes that are important to conserve to maintain nursery production and replenishment of recipient 
ecosystems. Ongoing degradation of coastal ecosystems increases the imperative for more

complete understanding. Rapid loss of nursery habitats and escalating habitat fragmentation identification of nursery habitats at a whole of habitat-unit scale, as is currently advocated, will not suffice in fragmented seascapes or in the face of specific impacts at particular

474 locations. Consequently, an understanding of the complex processes that underlie nursery 475 function is needed to support selection of appropriate fragments that can still provide key nursery functions. Failure to incorporate this complexity into conservation approaches and reserve design risks incomplete or inaccurate identification of key habitats and connectivities, and leads to significant potential for unexpected negative outcomes (Harris and Heathwaite 2012). Our current perspective provides a conceptual framework that can aid progress towards more complete understanding of nursery ground value, utilising data that are already available in the literature. It is only by continuing development of detailed understanding of the true value of nursery grounds and their functioning that we can hope to effectively protect these systems into the future.

\section{Acknowledgements}

We thank R. Vasconcelos and anonymous reviewers for comments that improved this manuscript.

\section{$489 \quad$ Figure Captions}

490 Figure 1: Components of Nursery Ground Value. Each component is described and discussed in the text.

Figure 2: Support of recipient ecosystems from nursery grounds is more than just export of new individuals to adult stocks and the biologically mediated nutrient translocation they represent (a). Individuals lost through mortality within the nursery facilitate the survival of those that ultimately emigrate (b), as prey participate in the continued transfer of biomass to local (c) and immigrating predators that feed in the nursery and subsequently move to 
webs that support nursery value (e), contribute to trophic relays as they are fed on during emigration (f), and influence key processes in recipient ecosystems (g).

\section{References}

Able, K. W. 2005. A re-examination of fish estuarine dependence: Evidence for connectivity between estuarine and ocean habitats. Estuarine, Coastal and Shelf Science 64:5-17.

Abrantes, K. and M. Sheaves. 2009a. Food web structure in a near-pristine mangrove area of the Australian Wet Tropics. Estuarine Coastal and Shelf Science 82:597-607.

Abrantes, K. and M. Sheaves. 2009b. Sources of nutrition supporting juvenile penaeid prawns in an Australian dry tropics estuary. Marine and Freshwater Research 60:949-959.

Abrantes, K. and M. Sheaves. 2010. Importance of freshwater flow in terrestrial-aquatic energetic connectivity in intermittently connected estuaries of tropical Australia. Marine Biology 157:2071-2086.

Albuquerque, C. Q., N. Miekeley, J. H. Muelbert, B. D. Walther, and A. J. Jaureguizar. 2012. Estuarine dependency in a marine fish evaluated with otolith chemistry. Marine Biology 159:2229-2239.

Alofs, K. M. and K. M. Polivka. 2004. Microhabitat-scale influences of resources and refuge on habitat selection by an estuarine opportunist fish. Marine Ecology Progress Series 271:297-306.

Attrill, M. J. and M. Power. 2004. Partitioning of temperature resources amongst an estuarine fish assemblage. Estuarine Coastal and Shelf Science 61(4), December 2004: 725-738.

Baker, R., M. Fujiwara, and T. Minello. 2014. Juvenile growth and mortality effects on white shrimp Litopenaeus setiferus population dynamics in the northern Gulf of Mexico. Fisheries Research 155:74-82.

Baker, R., B. Fry, L. Rozas, and T. Minello. 2013. Hydrodynamic regulation of salt marsh contributions to aquatic food webs. Marine Ecology Progress Series 490:37-52.

Baker, R. and M. Sheaves. 2005. Redefining the piscivore assemblage of shallow estuarine nursery habitats. Marine Ecology-Progress Series 291:197-213.

Baker, R. and M. Sheaves. 2007. Shallow-water refuge paradigm: conflicting evidence from tethering experiments in a tropical estuary. Marine Ecology-Progress Series 349:13-22.

Baker, R. and M. Sheaves. 2009a. Overlooked small and juvenile piscivores dominate shallow-water estuarine "refuges" in tropical Australia. Estuarine Coastal and Shelf Science 85:618-626.

Baker, R. and M. Sheaves. 2009b. Refugees or ravenous predators: detecting predation on new recruits to tropical estuarine nurseries. Wetlands Ecology and Management 17:317-330.

Ball, J. R., D. Esler, and J. A. Schmutz. 2007. Proximate composition, energetic value, and relative abundance of prey fish from the inshore eastern Bering Sea: implications for piscivorous predators. Polar Biology 30:699-708. 
Baltz, D. M., J. W. Fleeger, C. F. Rakocinski, and J. N. McCall. 1998. Food, density, and microhabitat: factors affecting growth and recruitment potential of juvenile saltmarsh fishes. Environmental Biology of Fishes 53:89-103.

Bassett, A., E. Barborne, M. Elliott, B. Li, S. E. Jorgensen, P. Lucena-Moya, I. Pardo, and D. Mouillot. 2013. A unifying approach to understanding transitional waters: Fundamental properties emerging from ecotone ecosystems. Estuarine Coastal and Shelf Science 132:5-16.

Beck, M. W., K. L. Heck, Jr., K. W. Able, D. L. Childers, D. B. Eggleston, B. M. Gillanders, B. Halpern, C. G. Hays, K. Hoshino, T. J. Minello, R. J. Orth, P. F. Sheridan, and M. P. Weinstein. 2001. The identification, conservation, and management of estuarine and marine nurseries for fish and invertebrates. Bioscience 51:633-641.

Beger, M., H. S. Grantham, R. L. Pressey, K. A. Wilson, E. L. Peterson, D. Dorfman, P. J. Mumby, R. Lourival, D. R. Brumbaugh, and H. P. Possingham. 2010. Conservation planning for connectivity across marine, freshwater, and terrestrial realms. Biological Conservation 143:565-575.

Begg, G. A. and G. A. Hopper. 1997. Feeding patterns of school mackerel (Scomberomorus queenslandicus) and spotted mackerel (S. munroi) in Queensland east-coast waters. Marine and Freshwater Research 48:565-571.

Berkström, C., M. Gullström, R. Lindborg, A. W. Mwandya, S. A. S. Yahya, N. Kautsky, and M. Nyström. 2012. Exploring 'knowns' and 'unknowns' in tropical seascape connectivity with insights from East African coral reefs. Estuarine, Coastal and Shelf Science 107:1-21.

Boesch, D. F. and R. E. Turner. 1984. Dependence of fishery species on salt marshes: the role of food and refuge. Estuaries and Coasts 7: 460-468.

Bouillon, S., R. Connolly, and S. Y. Lee. 2008. Organic matter exchange and cycling in mangrove ecosystems: Recent insights from stable isotope studies. Journal of Sea Research 59:44-58.

Brown, C. A., S. A. Holt, G. A. Jackson, D. A. Brooks, and G. J. Holt. 2004. Simulating larval supply to estuarine nursery areas: how important are physical processes to the supply of larvae to the Aransas Pass Inlet? Fisheries Oceanography 13:181-196.

Camp, A. L., C. H. Ryer, B. Laurel, and K. Seals. 2011. Effect of nursery habitat on densitydependent habitat selection in juvenile flatfish. Journal of Experimental Marine Biology and Ecology 404:15-20.

Connolly, R. M., J. S. Hindell, and D. Gorman. 2005. Seagrass and epiphytic algae support nutrition of a fisheries species, Sillago schomburgkii, in adjacent intertidal habitats. Marine Ecology Progress Series 286:69-79.

Corn, M. and C. Copeland. 2010. The Deepwater Horizon oil spill: coastal wetland and wildlife impacts and response. Congressional Research Service.

Curtis, T. H., D. H. Adams, and G. H. Burgess. 2011. Seasonal Distribution and Habitat Associations of Bull Sharks in the Indian River Lagoon, Florida: A 30-Year Synthesis. Transactions of the American Fisheries Society 140:1213-1226.

Dahlgren, C. P. and D. B. Eggleston. 2000. Ecological processes underlying ontogenetic habitat shifts in a coral reef fish. Ecology 81:2227-2240. 

J. A. Ley, I. Nagelkerken, and J. E. Serafy. 2006. Marine nurseries and effective juvenile habitats: concepts and applications. Marine Ecology Progress Series 312:291-295.

580 Davis, B., R. Johnston, R. Baker, and M. Sheaves. 2012. Fish utilisation of wetland nurseries with complex hydrological connectivity. PLoS ONE 7:e49107.

Deegan, L. 1993. Nutrient and energy transport between estuaries and coastal marine ecosystems by fish migrations. Canadian Journal of Fisheries and Aquatic Sciences 50:74-79.

Del Toro-Silva, F. M., J. M. Miller, J. C. Taylor, and T. A. Ellis. 2008. Influence of oxygen and temperature on growth and metabolic performance of Paralichthys lethostigma (Pleuronectiformes: Paralichthyidae). Journal of Experimental Marine Biology and Ecology 358:113-123. 85:2422-2428.

Dorenbosch, M., M. G. G. Grol, A. de Groene, G. van der Velde, and I. Nagelkerken. 2009. Piscivore assemblages and predation pressure affect relative safety of some back-reef habitats for juvenile fish in a Caribbean bay. Marine Ecology Progress Series 379:181-196.

Dorenbosch, M., M. G. G. Grol, I. Nagelkerken, and G. Van der Velde. 2005. Distribution of coral reef fishes along a coral reef-seagrass gradient: edge effects and habitat segregation. Marine Ecology Progress Series 299:277-288.

Elliott, M., and Kennish, M. J. 2011. Chapter 8.01: Introduction - Human induced problems (Uses and Abuses). In: McLusky, D. S., Wolanski, E. (Eds.), Treatise on Estuaries and Coasts. Elsevier, Amsterdam.

600 Elliott, M., and A. K. Whitfield. 2011. Challenging paradigms in estuarine ecology and 601 management. Estuarine Coastal and Shelf Science 94:306-314.

\section{Elliott, M., A. K. Whitfield, I. C. Potter, S. J. M. Blaber, D. P. Cyrus, F. G. Nordie, and T. D.} Harrison. 2007. The guild approach to categorizing estuarine fish assemblages: a global review. Fish and Fisheries 8:241-268.

Ellis, T. and R. N. Gibson. 1995. Size-selective predation of 0-group flatfishes in a Scottish coastal nursery ground. Marine ecology progress series. Oldendorf 127:27-37.

Foley, M. M., B. S. Halpern, F. Micheli, M. H. Armsby, M. R. Caldwell, C. M. Crain, E. Prahler, N. Rohr, D. Sivas, M. W. Beck, M. H. Carr, L. B. Crowder, J. E. Duffy, S. D. Hacker, K. L. Mcleod, S. R. Palumbi, C. H. Peterson, H. M. Regan, M. H. Ruckelshaus, P. A. Sandifer, and R. S. Steneck. 2010. Guiding ecological principles for marine spatial planning. Marine Policy 34:955-966.

Friedland, K. D., J. P. Manning, J. S. Link, J. R. Gilbert, A. T. Gilbert, and A. F. O'Connell. 2012. Variation in wind and piscivorous predator fields affecting the survival of Atlantic salmon, Salmo salar, in the Gulf of Maine. Fisheries Management and Ecology 19:22-35.

615 Froeschke, B. F., G. W. Stunz, M. M. Reese Robillard, J. Williams, and J. T. Froeschke. 616 2013. A modeling and field approach to identify essential fish habitat for juvenile Bay Whiff 
617 (Citharichthys spilopterus) and Southern Flounder (Paralichthys lethostigma) within the 618 Aransas Bay complex, TX. Estuaries and Coasts 36:881-892.

619 Gartland, J., R. J. Latour, A. D. Halvorson, and H. M. Austin. 2006. Diet Composition of 620 Young-of-the-Year Bluefish in the Lower Chesapeake Bay and the Coastal Ocean of 621 Virginia. Transactions of the American Fisheries Society 135:371-378.

622 Gillanders, B. M. 2005. Using elemental chemistry of fish otoliths to determine connectivity 623 between estuarine and coastal habitats. Estuarine, Coastal and Shelf Science 64:47-57.

624 Gillanders, B. M., K. W. Able, J. A. Brown, D. B. Eggleston, and P. F. Sheridan. 2003.

625 Evidence of connectivity between juvenile and adult habitats for mobile marine fauna: An 626 important component of nurseries. Marine Ecology Progress Series 247:281-295.

627 Gillanders, B. M. and M. J. Kingsford. 1996. Elements in otoliths may elucidate the 628 contribution of estuarine recruitment to sustaining coastal reef populations of a temperate reef 629 fish. Marine Ecology Progress Series 141:13-20.

630 Gorman, A. M., R. S. Gregory, and D. C. Schneider. 2009. Eelgrass patch size and proximity 631 to the patch edge affect predation risk of recently settled age 0 cod (Gadus). Journal of 632 Experimental Marine Biology and Ecology 371:1-9.

633 Grol MGG, Nagelkerken I, Rypel AL, Layman CA (2011) Simple ecological trade-offs give 634 rise to emergent cross-ecosystem distributions of a coral reef fish. Oecologia 165: 79-88

635 Guest, M. A. and R. M. Connolly. 2004. Fine-scale movement and assimilation of carbon in 636 saltmarsh and mangrove habitat by resident animals. Aquatic Ecology 38:599-609.

637 Halpin, P. 2000. Habitat use by an intertidal salt-marsh fish: trade-offs between predation and 638 growth. Marine Ecology Progress Series 198:203-214.

639 Hammerschlag, N., M. Heithaus, and J. Serafy. 2010. Influence of predation risk and food 640 supply on nocturnal fish foraging distributions along a mangrove-seagrass ecotone. Marine 641 Ecology Progress Series 414:223-235.

642 Harris, G. P. and A. Heathwaite. 2012. Why is achieving good ecological outcomes in rivers 643 so difficult? Freshwater Biology 57:91-107.

644 Harrison, T. D. and A. K. Whitfield. 2006. Temperature and salinity as primary determinants 645 influencing the biogeography of fishes in South African estuaries. Estuarine Coastal and 646 Shelf Science 66(1-2), January 2006: 335-345.

647 Harter, S. L. and K. L. Heck, Jr. 2006. Growth rates of juvenile pinfish (Lagodon 648 rhomboides) effects of habitat and predation risk. Estuaries and Coasts 29:318-327.

649 Heck, K., D. Nadeau, and R. Thomas. 1997. The nursery role of seagrass beds. Gulf of 650 Mexico Science 1997:50-54.

651 Heck, K. L., T. J. B. Carruthers, C. M. Duarte, A. R. Hughes, G. Kendrick, R. J. Orth, and S. 652 W. Williams. 2008. Trophic transfers from seagrass meadows subsidize diverse marine and 653 terrestrial consumers Ecosystems 11:1198-1210. 
Heupel, M. R. and C. A. Simpfendorfer. 2011. Estuarine nursery areas provide a lowmortality environment for young bull sharks Carcharhinus leucas. Marine Ecology-Progress Series 433:237-244.

Hughes, R., S. Williams, C. Duarte, K. j. Heck, and M. Waycott. 2009. Associations of concern: declining seagrasses and threatened dependent species. Frontiers in Ecology and the Envorinment 7:242-246.

Huijbers, C. M., I. Nagelkerken, A. O. Debrot, and E. Jongejans. 2013. Geographic coupling of juvenile adult habitat shapes spatial population dynamics of a coral reef fish. Ecology 94(8):1859-1870.

Hunsicker, M. E., R. J. Olson, T. E. Essington, M. N. Maunder, L. M. Duffy, and J. F. Kitchell. 2012. Potential for top-down control on tropical tunas based on size structure of predator-prey interactions. Marine Ecology-Progress Series 445:263-U535.

Hurst, T. and D. O. Conover. 2002. Effects of temperature and salinity on survival of youngof-the-year Hudson River striped bass (Morone saxatilis): Implications for optimal overwintering habitats. Canadian Journal of Fisheries and Aquatic Sciences 59:787-795.

Igulu MM, Nagelkerken I, van der Velde G, Mgaya YD (2013) Mangrove fish production is largely fuelled by external food sources: a stable isotope analysis of fishes at the individual, species, and community levels from across the globe. Ecosystems 16: 1336-1352

Johnston, R. and M. Sheaves. 2007. Small fish and crustaceans demonstrate a preference for particular small-scale habitats when mangrove forests are not accessible. Journal of Experimental Marine Biology and Ecology 353:164-179.

Jones, R. F., D. M. Baltz, and R. L. Allen. 2002. Patterns of resource use by fishes and macroinvertebrates in Barataria Bay, Louisiana. Marine Ecology-Progress Series 237:271289.

Kimirei IA, Nagelkerken I, Griffioen B, Wagner C, Mgaya YD (2011) Ontogenetic habitat use by mangrove/seagrass-associated coral reef fishes shows flexibility in time and space. Estuarine, Coastal and Shelf Science 92: 47-58

Kimirei I, Nagelkerken I, Trommelen M, Blankers P, van Hoytema N, Hoeijmakers D, Huijbers CM, Mgaya YD, Rypel AL (2013) What drives ontogenetic niche shifts of fishes in coral reef ecosystems? Ecosystems 16: 783-796

Kneib, R. T. 1997. The role of tidal marshes in the ecology of estuarine nekton. Oceanography and Marine Biology: an Annual Review 35:163-220.

MacGregor, J. M. and E. D. Houde. 1994. Onshore-offshore pattern and variability in distribution and abundance of bay anchovy, Anchoa mitchilli, eggs and larvae in Chesapeake Bay. Marine Ecology-Progress Series 138:15-25.

MacPherson, E. 1998. Ontogenetic shifts in habitat use and aggregation in juvenile sparid fishes. Journal of Experimental Marine Biology and Ecology 220:127-150.

Madon, S. P. 2002. Ecophysiology of juvenile California halibut Paralichthys californicus in relation to body size, water temperature and salinity. Marine Ecology-Progress Series 243:235-249. 
Maljkovic, A., T. E. van Leeuwen, and S. N. Cove. 2008. Predation on the invasive red lionfish, Pterois volitans (Pisces: Scorpaenidae), by native groupers in the Bahamas. Coral Reefs 27:501-501.

Marshall, A. D. and M. B. Bennett. 2010. The frequency and effect of shark-inflicted bite injuries to the reef manta ray Manta alfredi. African Journal of Marine Science 32:573-580.

McBride, R. S., T. C. MacDonald, R. E. Matheson, Jr., D. A. Rydene, and P. B. Hood. 2001. Nursery habitats for ladyfish, Elops saurus, along salinity gradients in two Florida estuaries. Fishery Bulletin. 99:443-458.

Melville, A. J. and R. M. Connolly. 2005. Food webs supporting fish over subtropical mudflats are based on transported organic matter not in situ microalgae. Marine Biology $148: 363-371$.

Milton, D., I. Halliday, M. Sellin, R. Marsh, J. Staunton-Smith, and J. Woodhead. 2008. The effect of habitat and environmental history on otolith chemistry of barramundi Lates calcarifer in estuarine populations of a regulated tropical river. Estuarine Coastal and Shelf Science 78:301-315.

Minello, T. J., K. W. Able, M. P. Weinstein, and C. G. Hays. 2003. Salt marshes as nurseries for nekton: testing hypotheses on density, growth and survival through meta-analysis. Marine Ecology-Progress Series 246:39-59.

Minello, T. J., L. P. Rozas, and R. Baker. 2012. Geographic variability in salt marsh flooding patterns may affect nursery value for fishery species. Estuaries and Coasts 35:501-514.

Minello, T. J., R. J. Zimmerman, and E. X. Martinez. 1989. Mortality of Young Brown Shrimp Penaeus aztecus in Estuarine Nurseries. Transactions of the American Fisheries Society 118:693-708.

Mumby, P. J., A. J. Edwards, J. E. Arias-Gonzalez, K. C. Lindeman, P. G. Blackwell, A. Gall, M. I. Gorczynska, A. R. Harborne, C. L. Pescod, H. Renken, C. C. C. Wabnitz, and G. Llewellyn. 2004. Mangroves enhance the biomass of coral reef fish communities in the Caribbean. Nature 427:533-536.

Mumby, P. J. and A. Hastings. 2008. The impact of ecosystem connectivity on coral reef resilience. Journal of Applied Ecology 45:854-862.

Myers, R., J. Baum, T. Sheperd, S. Powers, and C. Peterson. 2007. Cascading Effects of the Loss of Apex Predatory Sharks from a Coastal Ocean. Science 315:1846-1850

Nagelkerken, I. 2007. Are non-estuarine mangroves connected to coral reefs through fish migration? Bulletin of Marine Science 80:595-596.597.

Nagelkerken, I. 2009. Evaluation of nursery function of mangroves and seagrass beds for tropical decapods and reef fishes: patterns and underlying mechanisms. Pages 357-396 in Ecological connectivity among tropical coastal ecosystems, ed. I. Nagelkerken. Springer Netherlands.

Nagelkerken, I., M. Dorenbosch, W. Verberk, E. Chocheret de la Moriniere, and G. Van der Velde. 2000a. Importance of shallow-water biotopes of a Caribbean bay for juvenile coral reef fishes: Patterns in biotope association, community structure and spatial distribution. Marine Ecology Progress Series 202:175-192. 
Nagelkerken, I., M. Dorenbosch, W. Verberk, E. C. De la Moriniere, and G. van der Velde. 2000b. Day-night shifts of fishes between shallow-water biotopes of a Caribbean bay, with emphasis on the nocturnal feeding of Haemulidae and Lutjanidae. Marine Ecology Progress Series 194:55-64.

Nagelkerken I, van der Velde G, Verberk WCEP, Dorenbosch M (2006) Segregation along multiple resource axes in a tropical seagrass fish community. Marine Ecology Progress Series 308: 79-89

Nagelkerken, I., M. Sheaves, R. Baker, and R. Connolly. in press. The seascape nursery: a novel spatial approach to identify and manage nurseries for coastal marine fauna. Fish and Fisheries DOI: 10.1111/faf.12057

Nagelkerken, I. and G. van der Velde. 2002. Do non-estuarine mangroves harbour higher densities of juvenile fish than adjacent shallow-water and coral reef habitats in Curacao (Netherlands Antilles)? Marine Ecology Progress Series 245:191-204.

Nobriga, M. L. and F. Feyrer. 2008. Diet composition in San Francisco Estuary striped bass: does trophic adaptability have its limits? Environmental Biology of Fishes 83:509-517.

Ogden, J. C. 1988. The influence of adjacent systems on the structure and function of coral reefs. Proceedings of the International Coral Reef Symposium 1:123-129.

Pihl, L., S. P. Baden, and R. J. Diaz. 1991. Effects of periodic hypoxia on distribution of demersal fish and crustaceans. Marine Biology 108:349-360.

Potter, I. C., J. R. Tweedley, M. Elliott, and A. K. Whitfield. in press. The ways in which fish use estuaries: a refinement and expansion of the guild approach. Fish and Fisheries DOI: $10.1111 /$ faf. 12050.

Reis-Santos, P., B. M. Gillanders, S. E. Tanner, R. P. Vasconcelos, T. S. Elsdon, and H. N. Cabral. 2012. Temporal variability in estuarine fish otolith elemental fingerprints:

Implications for connectivity assessments. Estuarine, Coastal and Shelf Science 112:216-224.

Robertson, A. I. and N. C. Duke. 1987. Mangroves as nursery sites - comparisons of the abundance and species composition of fish and crustaceans in mangroves and other nearshore habitats in tropical Australia. Marine Biology 96:193-205.

Robertson, A. I. and N. C. Duke. 1990. Recruitment, growth and residence time of fishes in a tropical Australian mangrove system. Estuarine, Coastal and Shelf Science 31:723-743.

Rozas, L. P. and M. W. LaSalle. 1990. A comparison of the diets of Gulf killifish, Fundulus grandis Baird and Girard, entering and leaving a Mississippi brackish marsh. Estuaries 13:332-336.

Russell, D. J. and R. N. Garrett. 1985. Early life history of barramundi, Lates calcarifer (Bloch), in north-eastern Queensland. Australian Journal of Marine and Freshwater Research 36:191-201.

Sandin, S. A. and S. W. Pacala. 2005. Fish aggregation results in inversely density-dependent predation on continuous coral reefs. Ecology 86:1520-1530. 
Scharf, F. S., J. A. Buckel, K. A. Rose, F. Juanes, and J. H. Cowan, Jr. 2006. Effects of variable prey and cohort dynamics on growth of young-of-the-year estuarine bluefish: evidence for interactions between spring- and summer-spawned cohorts. Transactions of the American Fisheries Society 135(5), September 2006: 1266-1289.

Seymour, R. S., N. C. Wegner, and J. B. Graham. 2008. Body size and the air-breathing organ of the Atlantic tarpon Megalops atlanticus. Comparative Biochemistry and Physiology a-Molecular \& Integrative Physiology 150:282-287.

Sheaves, M. 1996a. Do spatial differences in the abundance of two serranid fishes in estuaries of tropical Australia reflect long term salinity patterns? Marine Ecology-Progress Series 137:39-49.

Sheaves, M. 1996b. Habitat-specific distributions of some fishes in a tropical estuary. Marine and Freshwater Research 47:827-830.

Sheaves, M. 1998. Spatial patterns in estuarine fish faunas in tropical Queensland: a reflection of interaction between long-term physical and biological processes? Marine and Freshwater Research 49:31-40.

Sheaves, M. 2005. Nature and consequences of biological connectivity in mangrove systems. Marine Ecology-Progress Series 302:293-305.

Sheaves, M. 2009. Consequences of ecological connectivity: the coastal ecosystem mosaic. Marine Ecology-Progress Series 391:107-115.

Sheaves, M. 2012. Ecosystem equivalence and the ability to generalise: insights from global consistencies in mangrove fish assemblages. Marine Ecology-Progress Series 461:137-149.

Sheaves, M., R. Baker, and R. Johnston. 2006. Marine nurseries and effective juvenile habitats: an alternative view. Marine Ecology-Progress Series 318:303-306.

Sheaves, M., R. Johnston, A. Johnson, R. Baker, and R. Connolly. 2013. Nursery function drives temporal patterns in fish assemblage structure in four tropical estuaries. Estuaries and Coasts 1:1-13.

Sheaves, M., R. Johnston, B. Molony, and G. Shepard. 2007. The effect of impoundments on the structure and function of fish fauna in a highly regulated dry tropics estuary. Estuaries and Coasts 30:507-517.

Sogard, S. M. 1992. Variability in growth rates of juvenile fishes in different estuarine habitats. Marine Ecology Progress Series 85:35-53.

Svenning, M. A., R. Borgstrom, T. O. Dehli, G. Moen, R. T. Barrett, T. Pedersen, and W. Vader. 2005. The impact of marine fish predation on Atlantic salmon smolts (Salmo salar) in the Tana estuary, North Norway, in the presence of an alternative prey, lesser sandeel (Ammodytes marinus). Fisheries Research 76:466-474.

Switzer, T. S., E. J. Chesney, and D. M. Baltz. 2009. Habitat selection by flatfishes in the northern Gulf of Mexico: Implications for susceptibility to hypoxia. Journal of Experimental Marine Biology and Ecology 381:S51-S64.

Thorson, T. B. 1971. Movement of bull sharks, Carcharhinus leucas, between caribbean sea and Lake Nicaragua demonstrated by tagging. Copeia 1971:336-338. 
Tupper, M. 2007. Idenitifaction of nursery habitats for commercially valuable humphead wrasse Chelinus undulates and large groupers (Pisces: Serranidae) in Palau. Marine Ecology Progress Series 332:189-199.

Vance, D. J., M. D. E. Haywood, s. D. S. Heale, R. A. Kenyon, N. R. Loneragan, and R. C. Pendrey. 1996. How far do prawns and fish move into mangroves? Distribution of juvenile banana prawns Penaeus merguiensis and fish in a tropical mangrove forest in northern Australia. Marine Ecology Progress Series 131:115-124.

van den Belt, M. 2011. Chapter 21.01: Ecological economics of estuaries and coasts. In: McLusky, D. S., Wolanski, E. (Eds.), Treatise on Estuaries and Coasts. Elsevier, Amsterdam.

Valentine, J. F., K. L. Heck, D. Blackmon, M. E. Goecker, J. Christian, R. M. Kroutil, B. J. Peterson, M. A. Vanderklift, K. D. Kirsch, and M. Beck. 2008. Exploited species impacts on trophic linkages along reef-seagrass interfaces in the Florida Keys. Ecological Applications 18:1501-1515.

Vasconcelos, R. P., D. B. Eggleston, O. LePape, and I. Tulp. In press. Patterns and processes of habitat-specific demographic variability in exploited marine species. ICES Journal of Marine Science. DOI:10.1093/icesjms/fst136.

Vasconcelos, R. P., P. Reis-Santos, M. J. Costa, and H. N. Cabral. 2011. Connectivity between estuaries and marine exnvironment: Integrating metrics to assess estuarine nursery function. Ecological Indicators 11(5):1123-1133.

Verweij, M. C. and I. Nagelkerken. 2007. Short and long-term movement and site fidelity of juvenile Haemulidae in back-reef habitats of a Caribbean embayment. Hydrobiologia 592:257-270.

Verweij, M. C., I. Nagelkerken, K. E. M. Hol, A. van den Beld, and G. van der Velde. 2007. Space use of Lutjanus apodus including movement between a putative nursery and a coral reef. Bulletin of Marine Science 81:127-138.

Vizzini, S., G. Sara, R. H. Michener, and A. Mazzola. 2002. The role and contribution of the seagrass Posidonia oceanica (L.) Delile organic matter for secondary consumers as revealed by carbon and nitrogen stable isotope analysis. Acta Oecologica 23:277-285.

Walters, C. and F. Juanes. 1993. Recruitment Limitation as a Consequence of Natural Selection for Use of Restricted Feeding Habitats and Predation Risk Taking by Juvenile Fishes. Canadian Journal of Fisheries and Aquatic Sciences 50:2058-2070.

Wannamaker, C. M. and J. A. Rice. 2000. Effects of hypoxia on movements and behavior of selected estuarine organisms from the southeastern United States. Journal of Experimental Marine Biology and Ecology 249:145-163.

Webb, S. D., S. H. Woodcock, and B. M. Gillanders. 2012. Sources of otolith barium and strontium in estuarine fish and the influence of salinity and temperature. Marine Ecology Progress Series 453:189-199.

Weinstein, M. P. 1979. Shallow marsh habitats as primary nurseries for fishes and shellfish, Cape Fear River, North Carolina. Fishery Bulletin 77:339-357.

Werner, E. E. and D. J. Hall. (1988) Ontogenetic habitat shifts in blugill: the foraging ratepredation risk trade-off. Ecology 69:1352-1366. 
854 Werry, J. M., S. Y. Lee, N. M. Otway, Y. Hu, and W. Sumpton. 2011. A multi-faceted

855 approach for quantifying the estuarine-nearshore transition in the life cycle of the bull shark,

856 Carcharhinus leucas. Marine and Freshwater Research 62:1421-1431.

857 Yamane, K., K. Shirai, Y. Nagakura, M. Yamaguchi, A. Takiya, T. Horii, N. Tanaka, S.

858 Yamane, T. Arai, and T. Otake. 2010. Spatial variation in otolith elemental composition of

859 the Pacific herring Clupea pallasii in northern Japan. Aquatic Biology 10:283-290.

860 Yanez-Arancibia, A., A. L. Lara Dominguez, and D. Pauly. 1994. Coastal lagoons as fish 861 habitats. Elsevier Oceanography Series 60:363-376.

862 Yurk, H. and A. W. Trites. 2000. Experimental Attempts to Reduce Predation by Harbor

863 Seals on Out-Migrating Juvenile Salmonids. Transactions of the American Fisheries Society 864 129:1360-1366. 


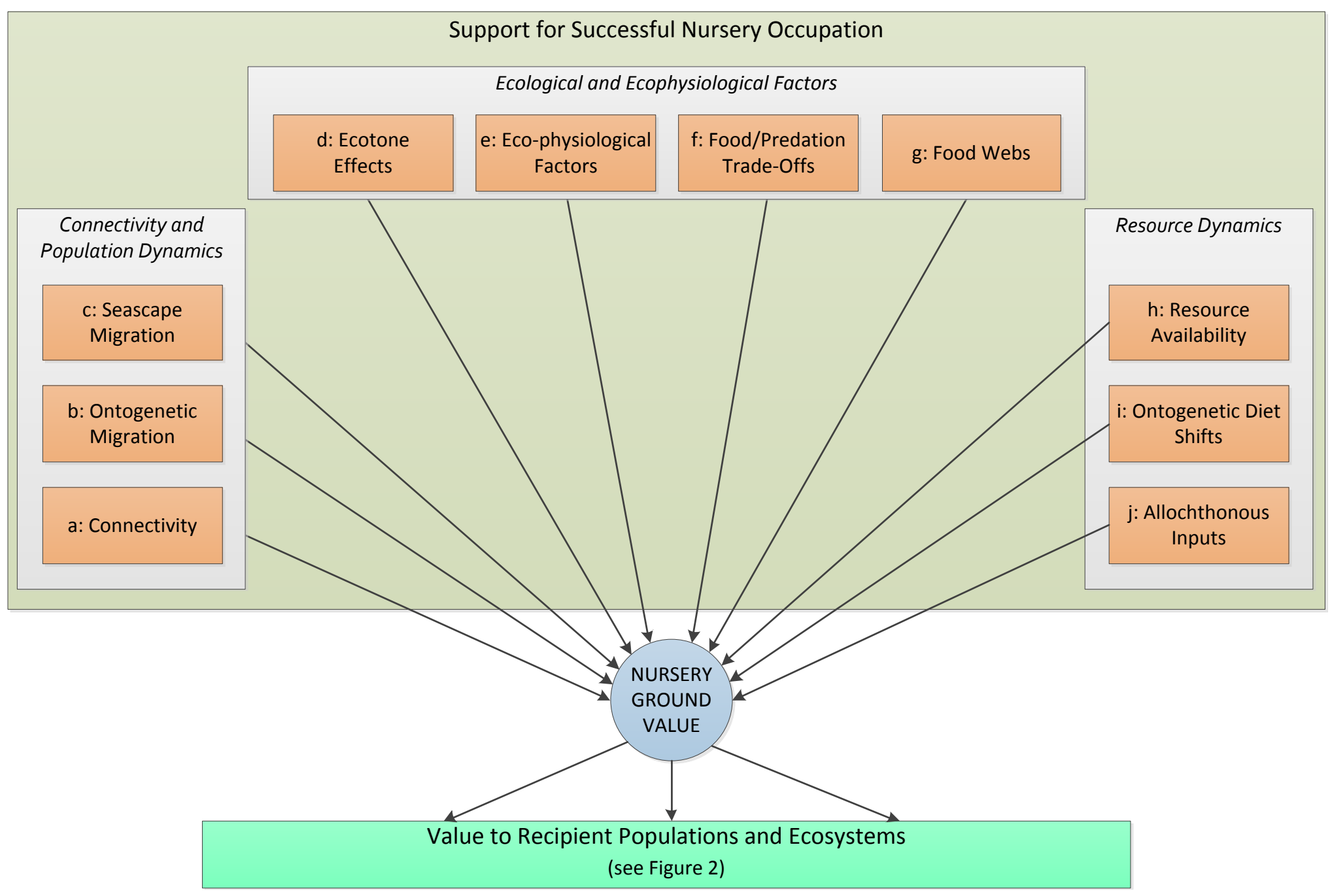

\section{Figure 1}




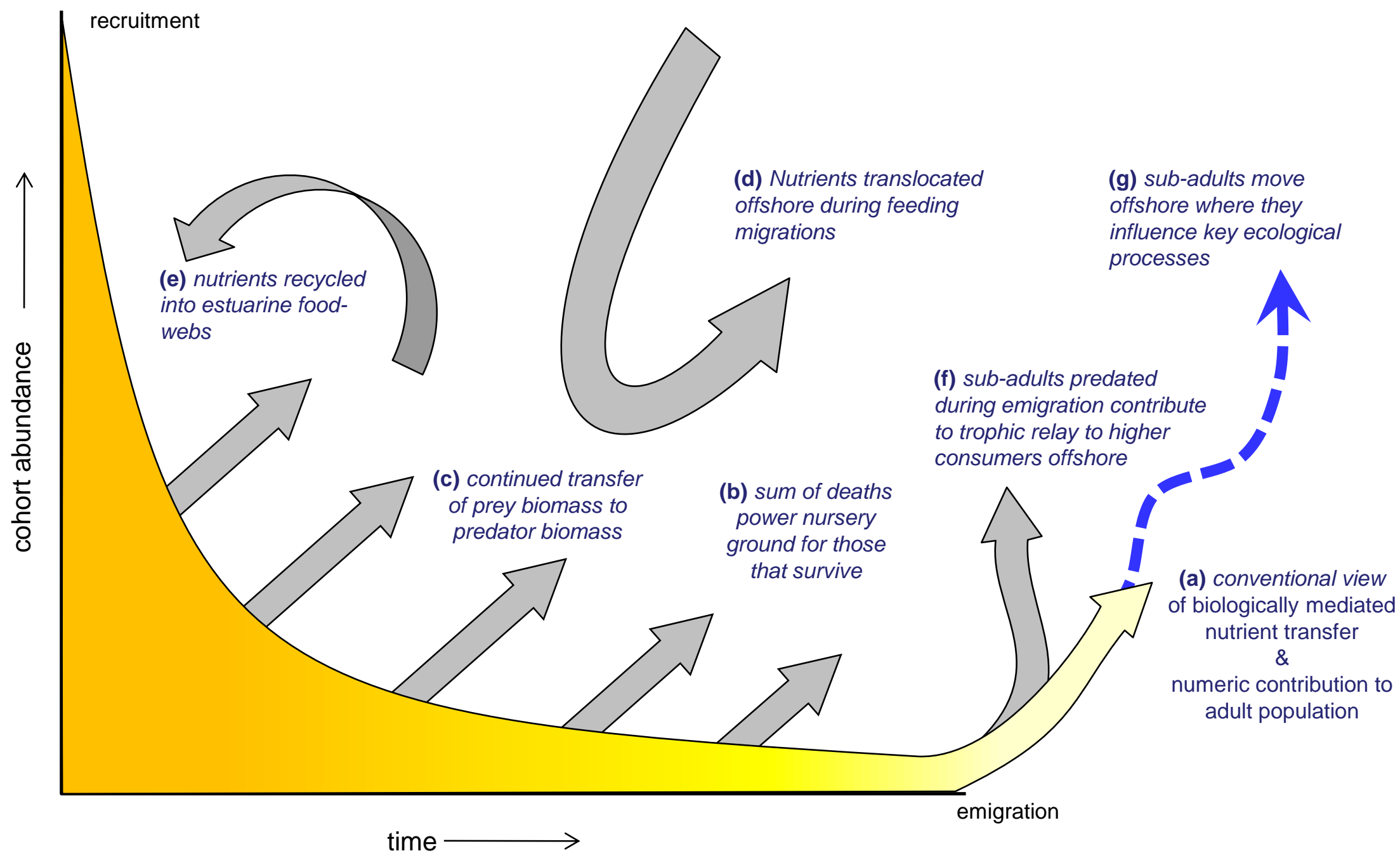

Figure 2 
Table 1: Solutions matrix: types of studies (bottom column titles) providing categories of information (top column titles) contributing to resolving aspects of nursery ground value (row information). Numbers at left reflect those in Fig. 1 (1a-1j) and Fig. 2 (2a-2e), hence $2 e$ depicted in Fig. 2 lies in the upper half of the table as part of 'Support for Nursery Occupation'. Temporal scales: short $=$ minutes to hours, meso $=$ days to weeks, life-history = a sequence of changes over time relating to life-history events, all $=$ relevant to all temporal scales. Spatial scales: local = within a local area or habitat, system = relating to a mosaic of habitats used by juveniles or a whole system (e.g. an estuary), all = relevant to all spatial scales.

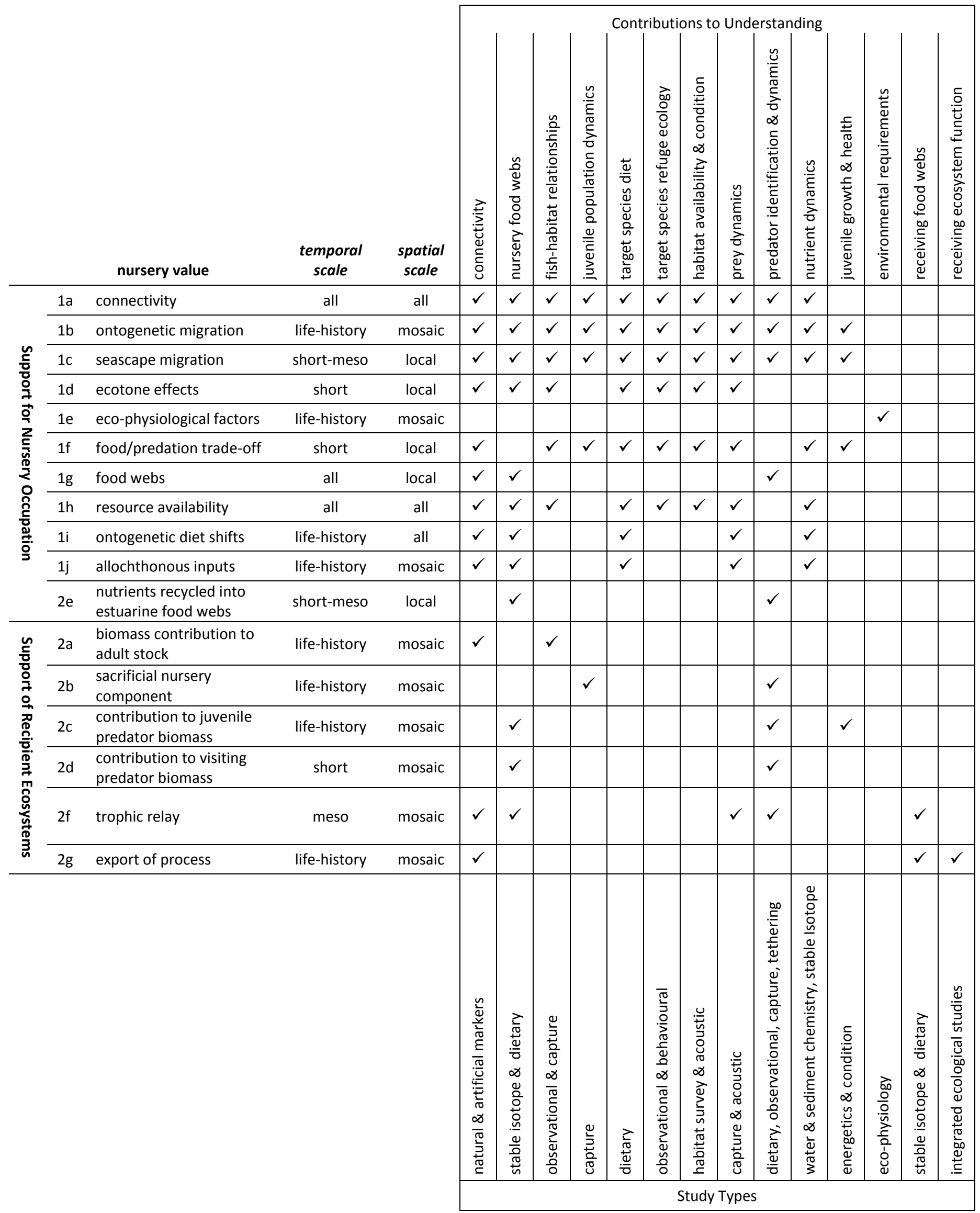

